\title{
The effectiveness of dexamethasone on the prognosis of dialysis patients with severe COVID-19
}

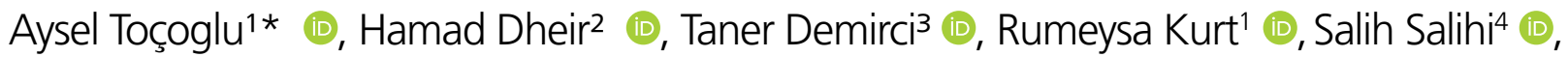

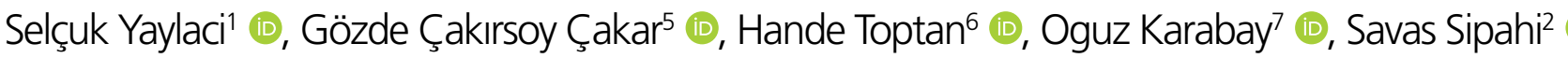

\section{SUMMARY}

OBJECTIVE: This study aimed to investigate the effectiveness of dexamethasone in dialysis patients with COVID-19 and whether it predicts mortality.

METHODS: This is a comparative cross-sectional study of 113 consecutive patients with COVID-19 with severe pneumonia signs. The patients were divided into two groups according to the use of dexamethasone treatment: group $1(n=45)$ included patients who were treated with dexamethasone and group $2(n=68)$ who did not receive dexamethasone.

RESULTS: The mean age of both groups was $67.0 \pm 10.6$ and $67.2 \pm 13.0$ years, respectively $(p=0.947)$. With respect to demographic and laboratory findings, there were no significant differences between the two groups ( $p>0.05)$. The hospitalization time of patients in group 1 was longer than that in group 2 ( 11 [7-17] days vs. 8 [5.3-14] days, $p=0.093$ ]. The 28-day survival rate was $54.2 \%$ in the group receiving dexamethasone treatment and $79.5 \%$ in the group not receiving dexamethasone treatment $(p=0.440)$.

CONCLUSION: Dexamethasone did not reduce mortality rates and the requirement for intensive care unit in dialysis patients with COVID19. Larger prospective randomized clinical trials are required to associate personalized medicine with the corticosteroid treatment to select suitable patients who are more likely to show a benefit.

KEYWORDS: Chronic kidney disease. COVID-19. Dexamethasone. Dialysis. Mortality.

\section{INTRODUCTION}

The new type of coronavirus (COVID-19 or SARS-CoV2) is a serious disease that causes severe acute respiratory failure and requires ward or intensive care units (ICUs) ${ }^{1}$. The risk of mortality increases with one or more comorbid conditions, such as advanced age, male gender, diabetes mellitus, hypertension, heart disease, chronic obstructive pulmonary disease, and chronic kidney disease, which are independent predictors of mortality ${ }^{2}$. Studies have shown that patients under renal replacement therapy are also associated with increased mortality rates due to COVID-19 disease ${ }^{3,4}$. The transmission risk of COVID-19 is very high when patients under hemodialysis (HD) program use transfer vehicles and undergo dialysis together in the same area of the dialysis center ${ }^{5}$. Accordingly,

\footnotetext{
'Sakarya University Faculty of Medicine, Department of Internal Medicine - Sakarya, Turkey.

${ }^{2}$ Sakarya University Faculty of Medicine, Division of Nephrology - Sakarya, Turkey.

${ }^{3}$ Sakarya University Faculty of Medicine, Division of Endocrinology - Sakarya, Turkey.

${ }^{4}$ Sakarya University Faculty of Medicine, Department of Cardiovascular Surgery - Sakarya, Turkey.

${ }^{5}$ Sakarya University Faculty of Medicine, Department of Clinic Pathology - Sakarya, Turkey.

${ }^{6}$ Sakarya University Faculty of Medicine, Department of Microbiology - Sakarya, Turkey.

${ }^{7}$ Sakarya University Faculty of Medicine, Department of Infection Diseases and Microbiology - Sakarya, Turkey.

*Corresponding author: agurkan@sakarya.edu.tr

Conflicts of interest: the authors declare there are no conflicts of interest. Funding: none.

Received on July 07, 2021. Accepted on August 10, 2021.
} 
the possibility of admission rates to the hospital wards and ICUs due to COVID-19 disease is expected to be higher in dialysis patients than in the normal population.

Many treatment approaches, such as convalescent plasma, remdesivir, and interleukin-6 inhibitors, have been suggested to treat the disease for selected patient populations, but they have controversial results ${ }^{6-11}$. Corticosteroid therapy has been shown as an effective treatment approach in the normal population ${ }^{12,13}$. A meta-analysis of the efficacy and safety of corticosteroids in non-COVID-19 patients with sepsis suggested that administration of corticosteroids was associated with reduced 28-day mortality compared with placebo use or standard supportive care ${ }^{14}$. Corticosteroids are commonly used as anti-inflammatory and immunosuppressive therapy in many diseases ${ }^{14-17}$.

Corticosteroids, especially due to high doses, also have many adverse systemic effects, such as obesity, hypertension, bone disorders, and hyperglycemia, that may predispose to cardiovascular disease in future ${ }^{18}$. In the dialysis population with COVID-19, having more than one comorbid disease, exposure to prolonged uremia, accompanying severe atherosclerotic diseases, and hypervolemia may cause more progressive respiratory failure, making the management of the clinical course and treatment options quite complicated. Generally, the treatment options of dialysis patients may not be successful because of their anuric nature and multiorgan pathologies, compared with normal populations.

This study aims to investigate the effectiveness of dexamethasone therapy in dialysis patients with COVID-19 and whether it predicts mortality in these patients.

\section{METHODS}

This descriptive comparative cross-sectional study was conducted on 113 dialysis patients with consecutive COVID-19 disease between March 15 and December 15, 2020. The study population was only composed of patients with confirmed COVID19 by real-time reverse transcription polymerase chain reaction (RT-PCR) taken from nasopharyngeal (NP) swab. The study was conducted in accordance with the Declaration of Helsinki and after the approval of the Ethics Committee of Sakarya University Faculty of Medicine ( $\mathrm{n}^{\circ}$ E-71522473-050.01.04640). The inclusion criteria in the study are

1. those who have been receiving HD or peritoneal dialysis (PD) treatment for at least three months,

2. patients with consecutive positive NP RT-PCR results, and

3. those who have severe disease criteria (respiratory rate $>30 / \mathrm{min}$, despite more than $5 \mathrm{~L} / \mathrm{min}$ of oxygen supporting, the oxygen saturation of patients is $<90 \%$, and/ or $\mathrm{PaO}_{2} / \mathrm{FiO}_{2}<300 \mathrm{~mm} \mathrm{Hg}$ ).
The patients who

1. underwent acute dialysis,

2. have negative NP RT-PCR,

3. have an active additional viral infection such as hepatitis $\mathrm{B}$ and $\mathrm{C}$ or human immunodeficiency virus, and

4. hospital record files inaccessible were excluded. The patients were not given steroid treatment between March 15 and July 20, 2020, because there was no evidence of successful steroid treatment as in the recovery study.

For this reason, patients were divided into two groups according to the use of dexamethasone treatment: group $1(n=45)$ included patients who were treated with dexamethasone and group $2(\mathrm{n}=68)$ who did not receive dexamethasone. Demographic and laboratory results of all patients were compared. Favipiravir (FVP) treatment was given to all patients in both groups. The FVP doses were given $1600 \mathrm{mg}$ twice daily and $1600 \mathrm{mg}$ one time in days $2-5$. All patients in group 1 received $8 \mathrm{mg}$ dexamethasone for at least 10 days.

Statistical analyses were performed using SPSS version 22 software. The suitability of the variables to normal distribution was examined using visual (histogram and probability graphs) and analytical methods (Kolmogorov-Smirnov). The chi-square test was used to determine whether there was any difference between the groups in terms of quality variables. Whether there is a difference between the groups in terms of numerical variables, or if parametric test conditions were fulfilled, independent groups were examined by $t$-test and, if not, Mann-Whitney U test was used. Continuous variables were expressed as means \pm standard deviation or medians (interquartile ranges). Categorical variables were expressed as the number of cases (percentage in brackets). The effect of dexamethasone use on the survival of dialysis patients with COVID-19 was investigated using the log-rank test. The Kaplan-Meier survival estimates were calculated. Statistical significance level was accepted as $\mathrm{p}<0.05$.

\section{RESULTS}

A total of 113 patients were enrolled in this study. Of these, 45 patients used dexamethasone (group 1) and 68 patients did not use dexamethasone (group 2). The mean age of both groups was $67.0 \pm 10.6$ and $67.2 \pm 13.0$ years, respectively $(\mathrm{p}=0.947)$. While $93 \%$ of the patients were HD patients, just $7 \%$ of the patients were PD patients.

There were no significant difference between patients groups with respect to symptoms of disease, comorbid conditions, basal hematologic, and basal biochemistry findings 
( $>0.05$ ) (Tables 1 and 2). The duration of the onset of symptoms to hospital admission was 3 (1.5-8) days in group 1 and $2(1-5)$ days in group $2(\mathrm{p}=0.082)$. The hospitalization time of patients in group 1 was longer than that in group 2 (11 [7-17] days vs. 8 [5.3-14] days, $\mathrm{p}=0.093$ ) (Table 1). In terms of treatment location, the patients of the two groups were followed up in the ward at a rate of 71.1 and $89.7 \%$ and in the ICU at a rate of 28.9 and $10.3 \%$, respectively $(\mathrm{p}=0.011)$ (Table 2). During hospitalization, the requirement to transfer to ICU in both groups was similar (28.9 and $27.9 \%$, respectively; $\mathrm{p}=0.913)$. The need for invasive mechanical ventilation in group 1 was higher than that in group $2(31.1$ versus $23.5 \%, \mathrm{p}=0.293)$. The mortality rates in group 1 were higher than that in group 2 (55.6 versus $38.2 \%, \mathrm{p}=0.070$ ). KaplanMeier's survival curves according to dexamethasone treatment are shown in Figure 1. The 28-day survival rate was $54.2 \%$ in the group receiving dexamethasone treatment (group 1) and $79.5 \%$ in the group not receiving dexamethasone treatment (group 2) $(\mathrm{p}=0.440)$.

\section{DISCUSSION}

To our knowledge, this is the first study to investigate the effectiveness of dexamethasone on dialysis patients with severe COVID-19 disease. We did not find a significant effect of dexamethasone treatment with respect to 28-day mortality in our dialysis patients. There was no significant difference between the two groups in terms of age, gender, dialysis model, and baseline admission laboratory findings of the patients. This shows that both groups were well matched, so we can say that we correctly demonstrated the ineffectiveness of dexamethasone on mortality in equal dialysis patient groups.

Table 1. Characteristics of demographic features at the admission of dialysis patients with COVID-19.

\begin{tabular}{|c|c|c|c|}
\hline & $\begin{array}{c}\text { Group } 1 \\
(\mathrm{n}=45)\end{array}$ & $\begin{array}{c}\text { Group } 2 \\
(\mathrm{n}=68)\end{array}$ & p-value \\
\hline \multicolumn{4}{|l|}{ Renal replacement therapy, n (\%) } \\
\hline Hemodialysis & $40(88.9)$ & 65 (95.6) & \multirow{2}{*}{0.174} \\
\hline Peritoneal dialysis & $5(11.1)$ & $3(4.4)$ & \\
\hline Age, years & $67.0 \pm 10.6(22-85)$ & $67.2 \pm 13.0(25-89)$ & 0.947 \\
\hline \multicolumn{4}{|l|}{ Gender } \\
\hline Female/Male (\%) & 25/20 (55.6/44.4) & 28/40 (41.2/58.8) & 0.134 \\
\hline \multicolumn{4}{|l|}{ Presenting symptom, n (\%) } \\
\hline Fever & $28(62.2)$ & $44(64.7)$ & 0.788 \\
\hline Cough & $13(28.9)$ & $32(47.1)$ & 0.053 \\
\hline Dyspnea & $26(57.8)$ & $31(45.6)$ & 0.205 \\
\hline Weakness & $28(62.2)$ & $29(42.6)$ & 0.042 \\
\hline Diarrhea & 0 & $3(4.4)$ & 0.153 \\
\hline Nausea and vomiting & $4(8.9)$ & $6(8.8)$ & 0.990 \\
\hline Anosmia & $1(2.2)$ & 0 & 0.398 \\
\hline Headache & 0 & $3(4.5)$ & 0.272 \\
\hline \multicolumn{4}{|l|}{ Chronic diseases, n (\%) } \\
\hline Diabetes & $21(46.7)$ & $34(50.0)$ & 0.729 \\
\hline Hypertension & $39(86.7)$ & $59(86.8)$ & 0.988 \\
\hline ASCVD & $21(46.7)$ & $24(35.3)$ & 0.227 \\
\hline COPD & $3(6.7)$ & $8(11.8)$ & 0.371 \\
\hline Malignancy & $4(8.9)$ & $4(5.9)$ & 0.542 \\
\hline The onset of symptoms, median (IQR) days & $3(1.5--8)$ & $2(1-5)$ & 0.082 \\
\hline Hospitalization time, median (IQR) days & $11(7-17)$ & $8(5.3-14)$ & 0.093 \\
\hline
\end{tabular}

ASCVD: atherosclerotic cardiovascular disease; COPD: chronic obstructive pulmonary disease. 
In animal experiments, it has been shown that 10 days of dexamethasone treatment has a very substantial antihypoxic effect on hypoxic mices ${ }^{19}$. Dexamethasone treatment has been shown to significantly reduce the 28-day mortality rates associated with COVID-19 disease in the normal population ${ }^{12,20}$. However, treatment approaches and their response rates of different disease states in dialysis patients may not be as in the normal population and the drugs must be used with caution, bearing in mind the potential development of serious side effects. In one study, COVID-19-related mortality rates in HD patients were found to be higher $(25.4 \%, 95 \%$ CI $21.3-29.9 ; \mathrm{p}<0.001)$ than the normal population ${ }^{3}$. Another study revealed that the incidence, mortality, and fatality rates in HD patients were $341 / 10,000$ patients, $94 / 10,000$ patients, and $27.7 \%$, respectively ${ }^{21}$. In our study, we found high mortality rates in dialysis patients using dexamethasone and those did not (55.6 versus $38.2 \%)$. It can be said that the majority of patients as well as dialysis patients of this study was accompanied by diabetes mellitus, hypertension, and heart disease and had severe disease criteria, which lead to more mortality rates. However, in the present study, there was a greater trend of increased mortality rates in patients who used dexamethasone compared with patients who did not use it. In fact,

Table 2. Comparison of laboratory findings and clinical processes between groups according to dexamethasone use.

\begin{tabular}{|c|c|c|c|}
\hline & $\begin{array}{c}\text { Group } 1 \\
(n=45)\end{array}$ & $\begin{array}{c}\text { Group } 2 \\
(n=68)\end{array}$ & p-value \\
\hline Creatinine, $\mathrm{mg} / \mathrm{dL}$ & $6.0 \pm 2.7$ & $5.9 \pm 2.6$ & 0.765 \\
\hline White blood cell count, $10^{3} / \mathrm{mm}^{3}$ & $6.80(4.82-8.85)$ & $5.6(4.45-7.59)$ & 0.109 \\
\hline Absolute lymphocyte count, $10^{3} / \mathrm{mm}^{3}$ & $0.74(0.48-1.14)$ & $0.80(0.47-1.07)$ & 0.893 \\
\hline Neutrophil-to-lymphocyte ratio & $6.57(3.42-14.70)$ & $5.86(3.52-10.60)$ & 0.395 \\
\hline Platelet count, $10^{3} / \mathrm{mm}^{3}$ & $170 \pm 69$ & $154 \pm 75$ & 0.259 \\
\hline C-reactive protein, mg/L & $113.9(43.4-218.6)$ & $81.6(30.1-158.1)$ & 0.242 \\
\hline Procalcitonin, $\mathrm{ng} / \mathrm{mL}$ & $1.17(0.49-4.32)$ & $1.06(0.45-5.51)$ & 0.826 \\
\hline Alanine aminotransferase, IU/L & $14.0(9.5-21.5)$ & $14.5(9.3-27.0)$ & 0.647 \\
\hline Aspartate aminotransferase, IU/L & $33.0(22.0-43.0)$ & $26.0(18.0-45.0)$ & 0.231 \\
\hline Fibrinojen, mg/dL & $465 \pm 148$ & $422 \pm 112$ & 0.122 \\
\hline D-Dimer, ng/mL & $1110(564-2405)$ & $931(557-2720)$ & 0.960 \\
\hline Albumin, g/L & $3.0 \pm 0.5$ & $3.1 \pm 0.6$ & 0.519 \\
\hline Ferritin, ng/mL & $1702(761-3187)$ & $1575(661-3367)$ & 0.946 \\
\hline Lactate, $\mathrm{mEq} / \mathrm{L}$ & $1.77 \pm 0.88$ & $1.38 \pm 0.48$ & 0.010 \\
\hline Interleukin-6, pg/mL (n=60) & $81.6(41.7-424.0)$ & $72.3(31.5-300.1)$ & 0.676 \\
\hline \multicolumn{4}{|l|}{ Treatment location at admission, n (\%) } \\
\hline Ward & $32(71.1)$ & $61(89.7)$ & \multirow{2}{*}{0.011} \\
\hline Intensive care unit & $13(28.9)$ & $7(10.3)$ & \\
\hline Recruitment to intensive care unit, $\mathrm{n}(\%)$ & $13(28.9)$ & $19(27.9)$ & 0.913 \\
\hline \multicolumn{4}{|l|}{ Mechanical ventilation support, $\mathrm{n}(\%)$} \\
\hline No & $30(66.7)$ & $52(76.5)$ & \multirow{3}{*}{0.293} \\
\hline Noninvasive mechanical ventilator & $1(2.2)$ & - & \\
\hline Invasive mechanical ventilator & $14(31.1)$ & $16(23.5)$ & \\
\hline \multicolumn{4}{|l|}{ Rehospitalization after discharge, n (\%) } \\
\hline No & $42(93.3)$ & $65(95.6)$ & \multirow{2}{*}{0.601} \\
\hline Yes & $3(6.7)$ & $3(4.4)$ & \\
\hline Mortality, n (\%) & $25(55.6)$ & $26(38.2)$ & 0.070 \\
\hline
\end{tabular}




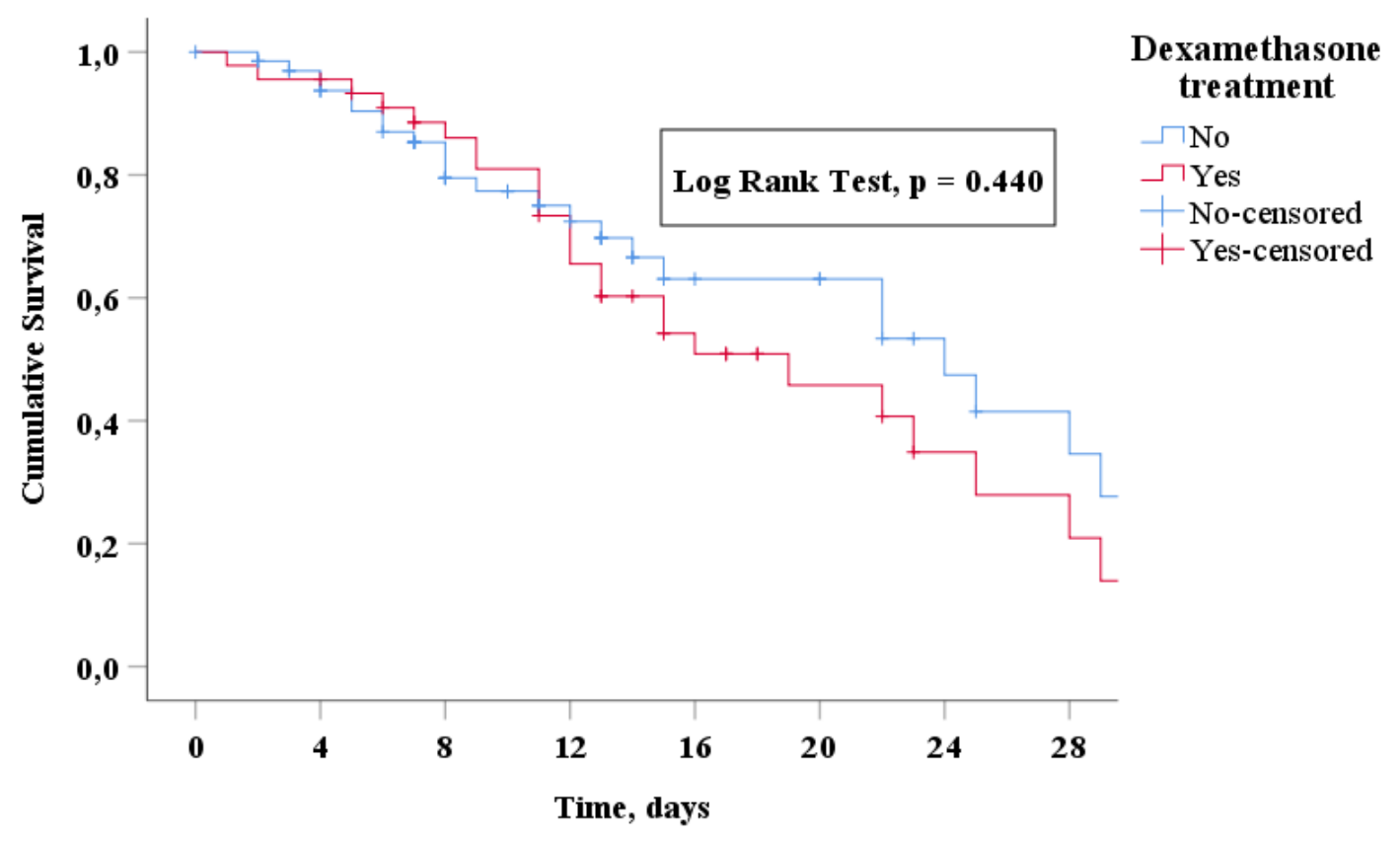

Figure 1. Overall survival according to dexamethasone use in dialysis patients with COVID-19.

compared with the other group, the dexamethasone group has more severe clinical courses, such as the fact that onethird of them were hospitalized directly in ICU from the emergency room, duration of symptom onset to hospital admission was longer, the hospitalization period was longer, and the levels of serum lactate were higher.

The hospitalization time of patients in group 1 was longer than that in group 2 (11 (7-17] days versus 8 [5.3-14] days, $\mathrm{p}=0.093$ ) (Tables 1 and 2). In one descriptive study with all probable 5327 patients with SARS, the average duration of onset of symptoms to hospital admission was 3.8 days and that of admission to discharge for those who survived was 29.7 days, while admission to death for casualties was 17.4 days ${ }^{22}$. The duration of onset of symptoms to admission was found to be an independent variable with respect to the prognosis of disease among the nondialytic patients with COVID-19 (95\%CI 1.05 [1.01-1.08], $\mathrm{p}=0.005)^{23}$. In the present study, the duration of onset of symptoms to hospital admission in the dexamethasone group was longer than the non-dexamethasone group. The difference between the two groups was close to significance. These outcomes need to be confirmed in future controlled studies involving more patients.

The limitations of the study are retrospective with a low number of patients in each group, not investigating acute side effects of steroids, lack of patients with mild or moderate severity illness in either group, not including normal COVID-19 patient group.

In conclusion, dexamethasone treatment did not reduce the 28-day mortality rates and need for ICUs in dialysis patients with COVID-19. This outcome may be due to the small number of study patients and the low number of patients who died. Larger prospective randomized clinical trials are required to associate personalized medicine with the corticosteroid treatment to select suitable uremic patients who are more likely to show a benefit.

\section{AUTHORS' CONTRIBUTION}

AT: Conceptualization, Methodology, Supervision, Writing Review \& Editing. HD: Conceptualization, Methodology, Writing-Review \& Editing. TD: Conceptualization, Validation, Writing - Review \& Editing. RK: Conceptualization, Validation, Writing - Review \& Editing. SS: Conceptualization, Validation, Writing-Review \& Editing. SY: Conceptualization, Methodology, Writing-Review \& Editing. GÇÇ: Conceptualization, Validation, Writing - Review \& Editing. HT: Conceptualization, Supervision, Writing - Review \& Editing. OK: Conceptualization, Supervision, Writing - Review \& Editing. SS: Conceptualization, Supervision, Writing - Review \& Editing. 


\section{REFERENCES}

1. Zhou F, Yu T, Du R, Fan G, Liu Y, Liu Z, et al. Clinical course and risk factors for mortality of adult inpatients with COVID-19 in Wuhan, China: a retrospective cohort study. Lancet. 2020;395(10229):1054-62. https://doi.org/10.1016/S01406736(20)30566-3

2. Du RH, Liang LR, Yang CQ, Wang $W, C$ ao TZ, Li M, et al. Predictors of mortality for patients with COVID-19 pneumonia caused by SARS-CoV-2. Eur Respir J. 2020;56(3):2002961. https://doi.org/10.1183/13993003.02961-2020

3. Ozturk S, Turgutalp K, Arici M, Odabas AR, Altiparmak MR, Aydin Z, et al. Mortality analysis of COVID-19 infection in chronic kidney disease, haemodialysis and renal transplant patients compared with patients without kidney disease: a nationwide analysis from Turkey. Nephrol Dial Transplant. 2020;35(12):2083-95. https://doi.org/10.1093/ndt/gfaa271

4. Hilbrands LB, Duivenvoorden R, Vart P, Franssen CFM, Hemmelder $\mathrm{MH}$, Jager KJ, et al. COVID-19-related mortality in kidney transplant and dialysis patients: results of the ERACODA collaboration. Nephrol Dial Transplant. 2020;35(11):1973-83. https://doi.org/10.1093/ndt/gfaa261

5. Xiong F, Tang H, Liu L, Tu C, Tian JB, Lei CT, et al. Clinical characteristics of and medical interventions for COVID-19 in hemodialysis patients in Wuhan, China. J Am Soc Nephrol. 2020;31(7):1387-97. https://doi.org/10.1681/ ASN.2020030354

6. Li L, Zhang W, Hu Y, Tong X, Zheng S, Yang J, et al. Effect of convalescent plasma therapy on time to clinical improvement in patients with severe and life-threatening COVID-19: a randomized clinical trial. JAMA. 2020;324(5):460-70. https:// doi.org/10.1001/jama.2020.10044

7. Sun $M, X u Y, H e H$, Zhang L, Wang X, Qiu Q, et al. A potentially effective treatment for COVID-19: a systematic review and meta-analysis of convalescent plasma therapy in treating severe infectious disease. Int J Infect Dis. 2020;98:334-46. https://doi.org/10.1016/j.ijid.2020.06.107

8. Beigel JH, Tomashek KM, Dodd LE, Mehta AK, Zingman BS, Kalil AC, et al. Remdesivir for the treatment of Covid-19 final report. N Engl J Med. 2020;383(19):1813-26. https:// doi.org/10.1056/NEJMoa2007764

9. Spinner CD, Gottlieb RL, Criner GJ, Arribas López JR, Cattelan AM, Viladomiu AS, et al. Effect of Remdesivir vs Standard care on clinical status at 11 days in patients with moderate COVID19: a randomized clinical trial. JAMA. 2020;324(11):1048-57. https://doi.org/10.1001/jama.2020.16349

10. Stone JH, Frigault MJ, Serling-Boyd NJ, Fernandes AD, Harvey L, Foulkes AS, et al. Efficacy of Tocilizumab in patients hospitalized with COVID-19. N Engl J Med. 2020;383(24):2333-44. https:// doi.org/10.1056/NEJMoa2028836

11. Rossotti R, Travi G, Ughi N, Corradin M, Baiguera C, Fumagalli $R$, et al. Safety and efficacy of anti-il6-receptor tocilizumab use in severe and critical patients affected by coronavirus disease 2019: a comparative analysis. J Infect. 2020;81(4):e11-7. https://doi.org/10.1016/j.jinf.2020.07.008
12. RECOVERY Collaborative Group, Horby P, Lim WS, Emberson JR, Mafham M, Bell JL, et al. Dexamethasone in hospitalized patients with Covid-19. N Engl J Med. 2021;384(8):693-704. https://doi.org/10.1056/NEJMoa2021436

13. Tomazini BM, Maia IS, Cavalcanti AB, Berwanger O, Rosa $R G$, Veiga VC, et al. Effect of Dexamethasone on days alive and ventilator-free in patients with moderate or severe acute respiratory distress syndrome and COVID-19: The CODEX randomized clinical trial. JAMA. 2020;324(13):1307-16. https://doi.org/10.1001/jama.2020.17021

14. Fang F, Zhang $Y$, Tang J, Lunsford LD, Li T, Tang R, et al. Association of corticosteroid treatment with outcomes in adult patients with sepsis: a systematic review and metaanalysis. JAMA Intern Med. 2019;179(2):213-23. https://doi. org/10.1001/jamainternmed.2018.5849

15. Barnes PJ. Glucocorticosteroids. In: Handbook of experimental pharmacology. New York: Springer; 2016. p.93-115.

16. Becker DE. Basic and clinical pharmacology of glucocorticosteroids. Anesth Prog. 2013;60(1):25-31;quiz 32. https://doi.org/10.2344/0003-3006-60.1.25

17. Lamb CA, Kennedy NA, Raine T, Hendy PA, Smith PJ, Limdi JK, et al. British Society of Gastroenterology consensus guidelines on the management of inflammatory bowel disease in adults. Gut. 2019;68(Suppl 3):s1-106. https://doi.org/10.1136/gutjnl2019-318484

18. Wei L, MacDonald TM, Walker BR. Taking glucocorticoids by prescription is associated with subsequent cardiovascular disease. Ann Intern Med. 2004;141(10):764-70. https://doi. org/10.7326/0003-4819-141-10-200411160-00007

19. Hosseinzadeh $\mathrm{MH}$, Shamshirian $\mathrm{A}$, Ebrahimzadeh MA. Dexamethasone vs COVID-19: An experimental study in line with the preliminary findings of a large trial. Int J Clin Pract. 2021;75(6):e13943. https://doi.org/10.1111/ijcp.13943

20. Sterne JAC, Murthy S, Diaz JV, Slutsky AS, Villar J, Angus $D C$, et al. Association between Administration of Systemic Corticosteroids and Mortality among Critically III Patients with COVID-19: A Meta-analysis. JAMA. 2020;324(13):1330-41. https://doi.org/10.1001/jama.2020.17023

21. Pio-Abreu A, Nascimento MM, Vieira MA, Menezes Neves PDM, Lugon JR, Sesso R. High mortality of CKD patients on hemodialysis with Covid-19 in Brazil. J Nephrol. 2020;33(5):875-7. https:// doi.org/10.1007/s40620-020-00823-z

22. Feng D, Jia N, Fang LQ, Richardus JH, Han XN, Cao WC, et al. Duration of symptom onset to hospital admission and admission to discharge or death in SARS in mainland China: a descriptive study. Trop Med Int Health. 2009;14(Suppl 1):2835. https://doi.org/10.1111/j.1365-3156.2008.02188.x

23. Liang WH, Guan WJ, Li CC, Li YM, Liang HR, Zhao Y, et al. Clinical characteristics and outcomes of hospitalised patients with COVID-19 treated in Hubei (epicentre) and outside Hubei (non-epicentre): a nationwide analysis of China. Eur Respir J. 2020;55(6):2000562. https://doi. org/10.1183/13993003.00562-2020 